\title{
Statistical characteristics for the type and length of deformation-induced cracks in columnar-grain ice
}

\author{
LORNE W. GOLD \\ Institute for Research and Construction, National Research Council of Canada, Ottawa, Ontario K1A OR6, Canada
}

\begin{abstract}
Observations are reported on cracks formed during compressive, unidirectional, constant-strain-rate deformation of columnar-grain ice. The axis of hexagonal crystallographic symmetry of each grain tended to be in the plane perpendicular to the long direction of the grains and to have a random orientation in that plane. For stress applied perpendicular to the long direction of the grains, the deformation was practically two-dimensional. It was found that the relative proportion of grain-boundary cracks increased with increasing strain rate, decreasing temperature and, for strain rate greater than $7 \times 10^{-5} \mathrm{~s}^{-1}$, with decreasing grain-size. Almost all the grain-boundary cracks had at least one edge at a triple point. For each test, the grain-boundary and transcrystalline crack lengths tended to have a log-normal distribution. The logarithmic mean crack length (LMCL) decreased with increasing strain rate, decreasing grain-size and decreasing temperature and tended to a constant value of $0.75 \mathrm{~mm}$ at $-10 \mathrm{C}$. For grain-size of $3 \mathrm{~mm}$ or greater, the LMCL had a maximum at a strain rate of $10^{-5}$ to $10^{-6} \mathrm{~s}^{-1}$ at $-10^{\circ} \mathrm{C}$. The LMCLs and the relative proportion of grain-boundary cracks tended to be normally distributed for given load conditions.
\end{abstract}

\section{INTRODUCTION}

Crack formation during deformation has received considerable attention in studies of the strength of granular and columnar-grain ice (Sinha, 1988, 1990; Schulson, 1990; Smith and Schulson, 1994). Gold (1972a, b) observed that the grain-boundary and transcrystalline crack populations induced by the deformation of columnar-grain ice may be the result of two distinct crack-forming processes that have well-defined statistical characteristics that depend on the conditions of loading and random properties of the ice structure. In the winter of 1991-92, the author, as a visiting scientist at the Institute for Marine Dynamics of the National Research Council of Canada, St John's, Newfoundland, carried out a research program whose objective was to obtain information on the dependence of grain-boundary and transcrystalline cracks on strain rate, grain-size and temperature, and on statistical characteristics of these crack populations, in order to further understanding of the role they play in the process of failure of polycrystalline ice. This paper presents justification for the expectation of a statistical behaviour, and statistical information on crack type and length.

\section{PREPARATION OF THE ICE AND TEST SPECIMENS}

The ice was made from deionised and deaerated water in an open-top tank measuring $55 \mathrm{~cm} \times 35 \mathrm{~cm} \times 25 \mathrm{~cm}$. After cooling in a cold room, freezing was initiated by spreading on the surface of the water ice particles of a given range in size, obtained by crushing and sieving large single crystals. A heated overflow tube, connected to the bottom of the tank, prevented the build-up of pressure due to expansion of the water on freezing. This method of making ice produced a columnar-grain structure that, within $30 \mathrm{~mm}$ of the seeded surface, had a strong tendency for the axis of hexagonal crystallographic symmetry of each grain to be in the plane perpendicular to the long direction of the grains and to have a random orientation in that plane. The average cross-section of the grains near the surface was determined by the size of the seed particles, and increased gradually in the direction of growth.

Clear rectangular specimens, $30 \mathrm{~mm} \times 90 \mathrm{~mm} \times 200 \mathrm{~mm}$, with the long direction of the grains perpendicular to the $90 \mathrm{~mm} \times 200 \mathrm{~mm}$ face, were used for the tests. The specimens, prepared with a milling machine, had sides and faces parallel to within $0.1 \mathrm{~mm}$ and end faces to better than $0.02 \mathrm{~mm}$. Each specimen was sealed in an airtight plastic bag and stored in an airtight box. They were conditioned at the test temperature for at least $24 \mathrm{~h}$ prior to testing.

\section{EXPERIMENTAL PROGEDURE}

A uniaxial compressive stress was applied to the $30 \mathrm{~mm} \times$ $90 \mathrm{~mm}$ end faces at a constant rate of cross-head displacement by a servo-controlled hydraulic actuator. It was, therefore, perpendicular to the long direction of the columnar grains and parallel to the plane in which the direction of the crystallographic axis of hexagonal symmetry of each grain was randomly distributed. Maximum stresses were limited to 3-5 $\mathrm{MPa}$, depending on the nominal strain rate and temperature. The nominal strain rates, $\dot{\varepsilon}_{\mathrm{1}}$, were $10^{-2}$, $10^{-3}, 10^{-4}$ and $10^{-5} \mathrm{~s}^{-1}$; the average measured values corresponding to these rates were $6.7 \times 10^{-3}, 7.6 \times 10^{4}, 7.6 \times 10^{-5}$ and $7.8 \times 10^{-6} \mathrm{~s}^{-1}$. Only two tests were done at the nominal rate of $10^{-2} \mathrm{~s}^{-1}$. Tests were conducted at the nominal rate of $10^{-3} \mathrm{~s}^{-1}$ at each of the temperatures $-5^{\circ},-10^{\circ},-20^{\circ}$ and $-30^{\circ} \mathrm{C}$. 
Strains were measured with two electrical extensometers mounted on the edges of specimens. The strain rate was found to be almost constant over the range of strain from $1.5 \times 10^{-4}$ to the maximum imposed during a test. For some tests the two measurements differed, but the relative change was small in comparison with that for the nominal rates. Values used in the analysis were the average of the two measurements. The average total strain, $\dot{\varepsilon}_{\mathrm{t}}$, was between $4.1 \times 10^{-4}$ and $9.6 \times 10^{-4}$.

Loads were applied through steel platens. The upper platen was self-adjusting to ensure full contact with the ends of the specimens. A small preload, less than $0.1 \mathrm{MPa}$ and small enough to allow positioning of the specimen on the lower platen, was applied for about $5 \mathrm{~min}$ before the beginning of each test. The output from the load cell, the two extensometers and the piston displacement transducer were sampled at a rate of $30-200 \mathrm{~Hz}$, depending on the nominal strain rate and temperature. A video camera, placed in front of the $90 \mathrm{~mm} \times 200 \mathrm{~mm}$ face, was used to monitor the formation of cracks. The formation of a crack was abrupt and easily detected by the reflection of light from two lamps, one on each side of the specimen.

For the type of ice and stress conditions used in the study, the cracks that form are long and narrow, with their long direction in the long direction of the grains. The sine of the angle between the surface of the cracks and the direction of the applied compressive stress appears to be normally distributed about that direction (Gold, 1966). There is a tendency for cracks to be displaced toward the surface with the larger average grain-size, probably because of the grain-size dependence of the strain and stress for crack initiation (Gold and others, 1993). Preliminary observations showed that for specimens $30 \mathrm{~mm}$ thick, practically all of the cracks extended through the central plane of the specimens. For strain rates greater than about $10^{-5} \mathrm{~s}^{-1}$, there was no visual evidence of cracks increasing in size for strains and stress less than $60 \%$ of yield or failure values. A few cases of crack enlargement after initial formation were observed in video records of tests conducted at the rate of $7.8 \times 10^{-6} \mathrm{~s}^{-1}$.

After completion of a test, the ends were cut from the specimen. The average grain-size perpendicular to the long direction of the grains was determined from thin sections cut from each face of the central part that remained. It was taken to be the diameter of the circle with area equal to the average grain area. The average for the specimen was the mean of the values for each face. Average grain-sizes for the tests carried out at $-10^{\circ} \mathrm{C}$ were in the range $2.3-9.2 \mathrm{~mm}$. At the other temperatures they were in the range 2.9 $6.2 \mathrm{~mm}$. The mean taper in the long direction of the grains for 64 specimens was $1^{\circ}$; the maximum was less than $2.4^{\circ}$.

After removal of the thin sections, the specimen was cut at its midplane and the new face of one smoothed by warming on a plate, whose temperature was just above $0^{\circ} \mathrm{C}$, until the cracks were seen clearly. The length of the cracks perpendicular to their long direction (hereafter called the crack length) within the central $70 \times 70 \mathrm{~mm}^{2}$ area of the face was measured to an accuracy of $0.05 \mathrm{~mm}$ using a calibrated scale mounted in the ocular of a binocular microscope. It was noted for each whether it was in the grain boundary or transcrystalline and whether it involved one or more grains. The position of grain-boundary cracks relative to the grain-boundary junction points (triple points) was observed, as well as whether they involved all or only part of the boundary. These measurements were made within $5 \mathrm{~h}$ of completion of the test. At the time of measurement, the edges of the cracks were sharp and distinct. There was no visual evidence during the period of measurement that they had begun to heal.

\section{STATISTICAL BASIS FOR THE ANALYSIS}

In addition to being elastically anisotropic, the resistance to viscous shear on the basal plane of an ice crystal, the plane perpendicular to the axis of hexagonal symmetry, is lower by a factor of about 100 than that for any other crystallographic plane. As the basal planes tended to be parallel to the long direction of the grains and the applied stress perpendicular to that direction, each grain had, effectively, only one direction for the initial delayed-elastic and nonelastic change of shape, and that was by slip on the basal plane in the direction of the resolved applied shear stress in the plane perpendicular to its long direction. As the shear stress in the long direction of the grains is small on both the basal planes and the grain boundaries, the initial deformation due to delayed-elastic and non-elastic strains would be virtually two-dimensional, their contribution in the long direction of the grains being much less than that in the plane perpendicular to it (Gold, 1960). For this plane-strain condition and constant volume deformation, each grain must have at least two degrees of freedom for deformation to conform to the change in shape of neighbouring grains (Gold, 1960).

For strain rates greater than $7.6 \times 10^{-5} \mathrm{~s}^{-1}$ at the temperature of $-10^{\circ} \mathrm{C}$, practically all the strain was recovered when the load was removed. Analysis of the stress and strain measurements showed that the strain for the three highest rates was primarily elastic plus delayed-elastic. Curvature of the stress-strain curve for the strain rate of $7.8 \times 10^{-6} \mathrm{~s}^{-1}$, and non-recoverable strain after the removal of the load, showed that, for this condition, permanent deformation had become significant (Gold, 1994). It would be expected that the delayed-clastic term would depend on grain-boundary shear, as hypothesised by Sinha (1979) and demonstrated for cyclical loading by Kuroiwa (1964), Nakamura and Abe (1979) and Cole (1991). It would depend also on the recoverable time-dependent deformation of the grains (Cole, 1993), and this would be affected by the anisotropy in the crystal structure of the ice. As each grain had, initially, only one degree of freedom for easy deformation, local stresses would be induced in the grain boundaries by, for example, grain distortion and grain-boundary shear, and in grains by, for example, the pile-up of dislocations. These stresses would depend on strain rate, time and the relative orientation of the crystallographic axis of adjacent grains. It would be expected that each local stress field would be of the scale of the grain-size and not be affected greatly by the relative orientation of grains some distance from the site. They would depend on immediately neighbouring grains, as the change in shape of a grain must conform with that of all grains in contact with its boundaries. If the local stress is sufficiently high, a crack may form and the deformation is no longer one of constant volume.

Because the axis of hexagonal symmetry of each grain is oriented randomly in the plane perpendicular to the long direction of the grains, there must be an equal probability of the occurrence of all possible combinations of crystallographic orientations for the three grains forming a triple 
point. Little is known about the nature of the singularities that cause local stress variations in ice. It would seem reasonable to assume, however, that the combination of such singularities and the random orientation of the crystallographic axes of symmetry would result in an internal strain-energy field with a variability that should be describable by a distribution function. If this is the case, the formation of a crack should tell something about the spatial and temporal variation in the internal strain energy, which is evolving in a manner that depends on the shape, size and relative crystallographic orientation of grains, the nature of the singularities and the time dependence of the stress and strain. The present study responds to the questions, for a simple experimental arrangement, what is the critical applied strain and stress at the time of the formation of a crack under plane-strain conditions, when and where do cracks form, and what are some of the statistical properties of the crack populations.

Assume that the formation of each crack is an independent, random event. Each test, therefore, can be considered as a set of concurrent, independent, experiments with the same external load conditions. The crack populations that develop during a test should give information on the probability distributions that may be used to describe the process. Additional tests extend this information base, as each specimen is a sample drawn from the universe of specimens for a particular type of ice of given average grain-size.

Assume that the initial, dominant, spatial variation in the stress and the strain in a specimen are determined by the relative crystallographic oricntations of the grains forming each triple point. The number of grains per $\mathrm{m}^{2}$ is given by $4 / \pi d^{2}$, where $d$ is the average grain-size as defined earlier. For the average grain-sizes of the specimens, the grain density of the ice is in the range $1.5 \times 10^{+}$to $24 \times 10^{4} \mathrm{~m}^{2}$. This means that the $70 \times 70 \mathrm{~mm}^{2}$ area of observation for each specimen would have 74-1200 grains. Each grain shares one-third of six triple points, and so the number of triple points per $\mathrm{m}^{2}$ is about twice the number of grains. That is, each specimen is a random sample of $150-2400$ grain-boundary triple points, depending on the average grain-size, of all possible combinations of relative crystallographic orientation of adjacent grains. The observations indicated that the number of grains for each specimen was sufficient to bring out statistical characteristics of the two crack populations.

\section{RESULTS}

\subsection{Crack type}

For the strain rate and stress imposed on the specimens, the majority of the cracks were in the grain boundaries, in marked contrast to what was found for the same type of ice when subjected to a creep strain of about $10^{2}$ and compressive stress of less than 2.0 MPa (Gold, 1972a, b). The grainboundary cracks could occupy the full boundary between two grains, part of the boundary, or more than one boundary. Practically every grain-boundary crack had at least one edge at a triple point.

Most transcrystalline cracks were wholly within one grain. Some had one edge at a grain boundary or at a triple point, and a few propagated through a boundary into an adjacent grain. Some of the cracks were a combination of transcrystalline and grain-boundary (tr-gb). Although it was possible to follow a crack through the ice with the microscope, it was not possible to establish if a tr-gb crack initiated within the grain or in a boundary. In the analysis, tr gb cracks were classified as transcrystalline.

Figure 1 shows the grain-size dependence of the ratio of the number of grain-boundary cracks to the total number of cracks (gb/tot) and of the ratio of the number of partial grain-boundary cracks to the total number of grain-boundary cracks (part/gb) for the nominal strain rate of $10^{-3} \mathrm{~s}^{-1}$. Shown also is the linear regression line for gb/tot. The equation and correlation coefficient for gb/tot for the nominal rates $10^{-3}, 10^{-4}$ and $10^{-5} \mathrm{~s}^{-1}$ are presented in Table 1 . It can be seen that the ratio decreased with increasing grain-size, but this dependence became less definite, and may even reverse, at the nominal strain rate of $10^{-5} \mathrm{~s}^{-1}$. The part/gb ratio tended to increase with grain-size, but the dependence became less definite at the nominal strain rate of $10^{-5} \mathrm{~s}^{-1}$. As the total number of cracks is the sum of the grain-boundary and transcrystalline cracks, the grain-size dependence of the ratio of transcrystalline to total number is readily visualised from Figure 1 and Table 1.

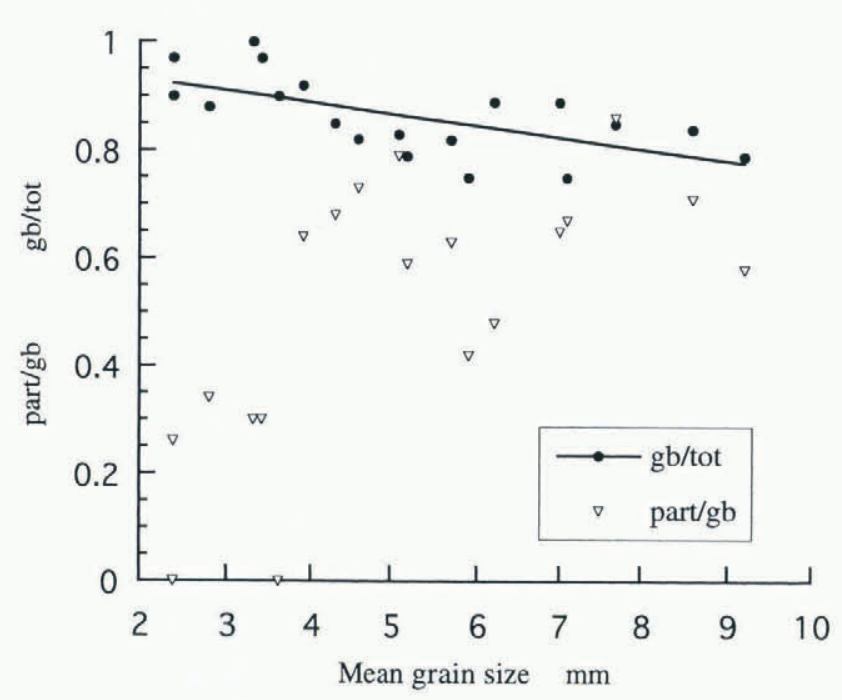

Fig. 1. Grain-size dependence of the crack ratios, $g b / t o t$ and part $/ \mathrm{g}$, for $\dot{\varepsilon}=7.6 \times 10^{-4} \mathrm{~s}^{-1} ; \mathrm{T}=-10^{\circ} \mathrm{C}$; total strain, $\varepsilon_{\mathrm{t}}$ (see Table 3). The equation for the linear regression line is given in Table 1.

The linear regression equation for the grain-size dependence for $\mathrm{gb} / \mathrm{tot}$ was used to calculate the mean ratio for each nominal strain rate and grain-sizes of 3, 5, 7 and $9 \mathrm{~mm}$. The resulting dependence of the mean ratios on actual average strain rate is shown in Figure 2. Because of the great scatter in the data for the nominal rate of $10^{-5} \mathrm{~s}^{-1}$,

Table 1. Linear regression equations and correlation coefficients for the ratio of grain-boundary cracks to total number of cracks for the nominal strain rate shown; $d$ is in $\mathrm{mm}$

\begin{tabular}{ccc} 
Nominal strain rate & Equation & $R$ \\
$\qquad \mathrm{~s}^{-1}$ & & \\
& & \\
\hline $10^{-3}$ & $\mathrm{gb} / \mathrm{tot}=0.97-0.021 d$ & 0.62 \\
$10^{-4}$ & $\mathrm{gb} / \mathrm{tot}=0.96-0.037 d$ & 0.64 \\
$10^{-5}$ & $\mathrm{gb} / \mathrm{tot}=0.56+0.03 d$ & 0.27
\end{tabular}




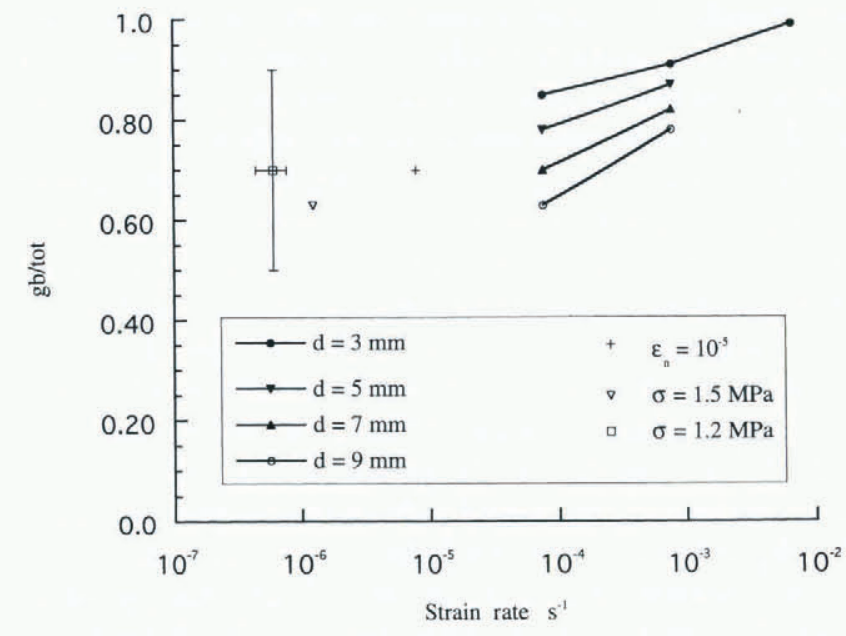

Fig. 2. Strain-rate dependence for the crack ratio, gb/tot, for given grain-size and constant strain-rate tests $\left(T=-10^{\circ} \mathrm{C}\right)$ and constant-load tests $\left(T=-9.5^{\circ} \mathrm{C}\right)$. The bars for the grain-boundary cracks for the load condition $\sigma=1.2 \mathrm{MPa}$ give the range in the ratio and the strain rate for 17 lests.

only the average value for all grain-sizes is plotted for this rate. The mean of the ratios for the two specimens tested at the nominal rate of $10^{-2} \mathrm{~s}^{-1}$ is included. One hundred and thirty cracks were measured for these specimens, of which one was $\operatorname{tr}^{-}$gb and all the others were grain-boundary with at least one edge at a triple point. The specimens had an average grain-size of 3.6 and $2.3 \mathrm{~mm}$, with a mean value of about $3 \mathrm{~mm}$. The plot shows that the gb/tot ratio for all grain-sizes tends to 1 at a strain rate of about $10^{-2} \mathrm{~s}^{-1}$.

Observations on grain-boundary and transcrystalline cracks were made in earlier studies using the same type of ice, but with a constant compressive stress applied perpendicular to the long direction of the grains. The average grain-size for this ice was $1.4-3.1 \mathrm{~mm}$, and the tests were carried out at a temperature of $-9.5^{\circ} \mathrm{C}$. Some tests, not previously reported, were carried out to strains in the same range as applied in the present work. One specimen was strained to $6.0 \times 10^{4}$ at an average rate of $1.25 \times 10^{-6} \mathrm{~s}$, by a stress of $1.5 \mathrm{MPa}$. The value of the ratio found for this test is given in Figure 2, along with the mean of the ratio for 17 specimens subjected to a strain of $4.4 \times 10^{-4}$ to $8.5 \times 10^{-4}$, imposed at an average rate in the range of $4.2 \times 10^{-7}$ to $7.3 \times 10^{-7} \mathrm{~s}^{-1}$, by a stress of $1.2 \mathrm{MPa}$.

The combined crack populations for three specimens of average grain-size about $3 \mathrm{~mm}$, strained in the earlier study to about $50 \times 10^{-4}$ under a constant stress of $0.7 \mathrm{MPa}$ and average strain rate of $1.46 \times 10^{-7} \mathrm{~s}^{-1}$, had a gb/tot ratio of 0.62. It was found that when columnar-grain ice of average grain-size in the same range was strained to about $10^{-2}$ under a constant stress of $1 \mathrm{MPa}$ or lower, the ratio was about 0.25 Gold, 1960, 1966, 1972a, b). It is clear that the relative proportion of grain-boundary cracks at a strain of about $6 \times 10^{-4}$ decreases with decreasing strain rate and, in the ductile range of behaviour, decreases with increasing strain. Kalifa and others (1989) found a similar decrease with decreasing strain rate for granular ice strained at rates greater than $10^{-4} \mathrm{~s}^{-1}$.

The gb/tot and transcrystalline to grain-boundary (tr/ $\mathrm{gb}$ ) ratios for the tests at temperatures of $-5^{\circ},-20^{\circ}$ and $-30^{\circ} \mathrm{C}$ are plotted in Figure 3. One test at $-5^{\circ} \mathrm{C}$ had to be deleted because the specimen broke during the test, and

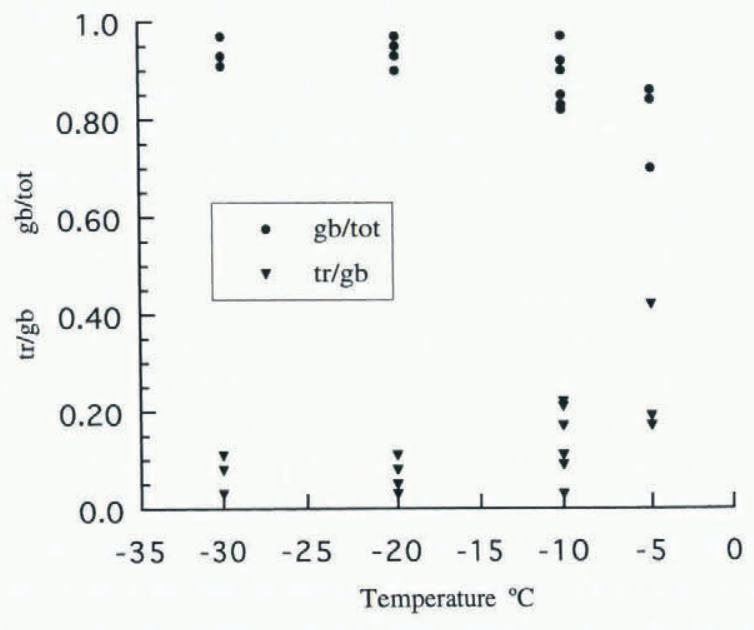

Fig. 3. Temperature dependence of the crack ratios, $g b / t o t$ and $\mathrm{tr} / \mathrm{g} b ; \dot{\varepsilon}_{\mathrm{n}}=10^{-3} \mathrm{~s}^{-1} ; \varepsilon_{\mathrm{t}} \sim 6 \times 10^{4} ;$ grain-size in the range $2.9-6.2 \mathrm{~mm}$.

one at $-30^{\circ} \mathrm{C}$ because there were too few cracks. The values for $-10^{\circ} \mathrm{C}$ are for six specimens with average grain-size in the range $3.4-5.1 \mathrm{~mm}$, tested at the nominal strain rate of $10^{-3} \mathrm{~s}^{-1}$. The limited number of tests suggest a tendency for $\mathrm{gb} /$ tot to increase with decreasing temperature.

The difference between the observed value for $\mathrm{gb} /$ tot and the mean value was determined for the 17 tests conducted under a constant load of $1.2 \mathrm{MPa}$, and for the tests carried out at the nominal strain rates of $10^{-3}, 10^{-4}$ and $10^{-5} \mathrm{~s}^{-1}$. For the latter group, the mean value for each specimen average grain-size was calculated from the linear regression equations given in Table 1 . Figure 4 presents on a normal probability coordinate system the differences for the constant-load case and for the nominal strain rate of $10^{-3} \mathrm{~s}^{-1}$. Shown also are the lines from a linear regression analysis of the percentage of specimens with differences less than or equal to a given value, using an exponential curve fit. The defining characteristics, $M_{1}$ and $M_{2}$, and correlation coefficient for the exponential curve are summarised for each condition in Table 2, along with the means and standard deviations determined from a statistical analysis of the differences. $M_{1}$ and $M_{2}$ have values that agree very closely with the corresponding means and standard deviations.

Table 2. The defining constants, $M_{1}$ and $M_{2}$ and the correlation coefficient, $R$, from an exponential curve fit to the differences, plotted on normal probability coordinates, between the actual and mean values of the ratio of grain-boundary to total cracks for the 17 tests with a constant stress of $1.2 \mathrm{MPa}$ $\left(T=-9.5^{\circ} \mathrm{C}\right)$, and for the actual and corresponding mean values determined from the grain-size dependence given in Table 1 , for the constant-strain-rate tests $\left(T=-10^{\circ} \mathrm{C}\right)$. Given also are the corresponding means and standard deviations (S.d.) from a statistical analysis of the differences; $\varepsilon_{\mathrm{t}} \sim 6 \times 10^{4}$

\begin{tabular}{lrlrll}
\hline Load condition & $M_{l}$ & $M^{2}$ & $R$ & Mean & S.d. \\
\hline$\dot{\varepsilon}_{\mathrm{n}}=10^{-3} \mathrm{~s}^{-1}$ & -0.003 & 0.055 & 0.98 & -0.003 & 0.056 \\
$\dot{\varepsilon}_{\mathrm{n}}=10^{-4} \mathrm{~s}^{-1}$ & 0.003 & 0.095 & 0.99 & 0.002 & 0.093 \\
$\dot{\varepsilon}_{\mathrm{n}}=10^{-5} \mathrm{~s}^{-1}$ & 0.003 & 0.17 & 0.99 & 0.003 & 0.17 \\
$\sigma=1.2 \mathrm{MPa}$ & 0.000 & 0.107 & 0.98 & 0.000 & 0.107
\end{tabular}




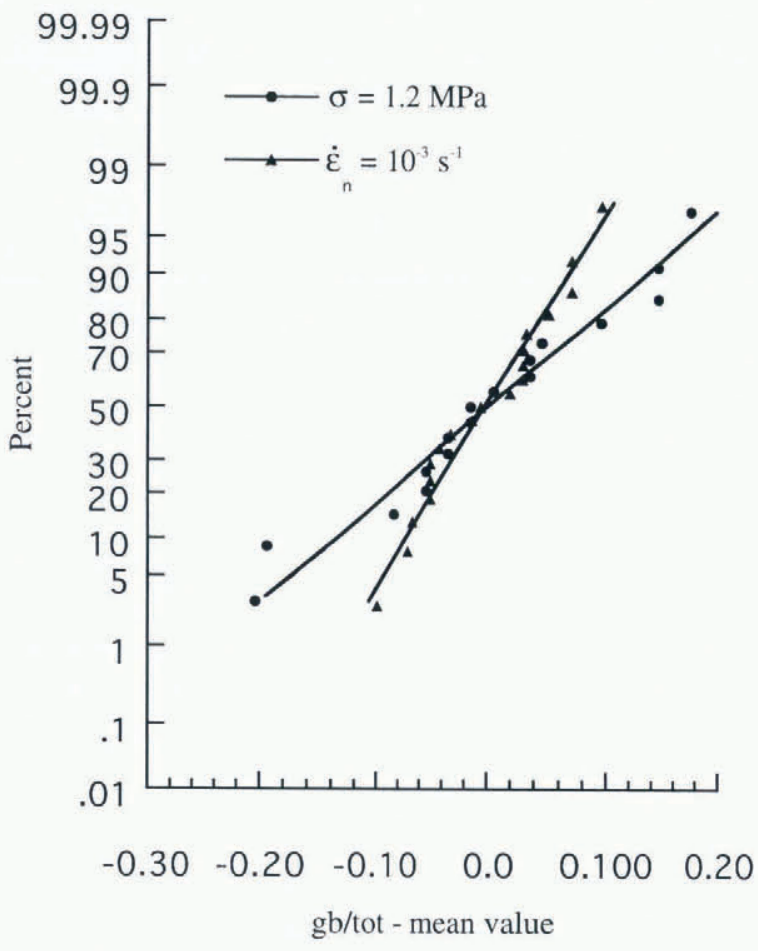

Fig. 4. The difference, plotted on normal probability coordinates, between the observed value of the crack ratio, gb/tot, for each test, and the mean value for the constant-load condition of $\sigma=1.2 \mathrm{MPa}\left(T=-9.5^{\circ} \mathrm{C}\right)$, and the mean value, corresponding to the grain-size, determined from the linear regression equation for $\dot{\varepsilon}_{\mathrm{n}}=10^{-3} \mathrm{~s}^{-1}\left(\mathrm{~T}=-10^{\circ} \mathrm{C}\right)$. The lines were obtained by an exponential curve fit to the results; $\varepsilon_{\mathrm{t}} \sim 6 \times 10^{4}$.

\subsection{Crack length}

It was observed in the earlier constant-load tests (Gold, 1972a) that the distribution in the length of all cracks formed in columnar-grain ice in a given strain of less than $15 \times 10^{-4}$ was described quite well by the log-normal distribution. This was found to be the case also for both the grainboundary and transcrystalline cracks formed under constant strain-rate conditions. Figure 5 shows on a log-normal probability coordinate system the distribution for 75 grainboundary cracks formed in the specimen of $2.3 \mathrm{~mm}$ average grain-size, strained at the nominal rate of $10^{-2} \mathrm{~s}^{-1}$.

The total number of grain-boundary cracks measured for each test at the nominal rates less than $10^{-2} \mathrm{~s}^{-1}$ was usually less than 40 , and so specimens were grouped by average grain-size in ranges of $1 \mathrm{~mm}$. Cracks for all specimens in a given range were combined to obtain a larger statistical sample. Results for the specimens in the grain-size ranges 3-4 and 5-6 mm, tested at the nominal rates of $10^{-3}$ and $10^{-5} \mathrm{~s}^{-1}$, respectively, are presented in Figure 5. The lines shown in the figure were obtained by statistical analysis of the crack lengths. Table 3 presents the number of cracks measured for each grain-size range, and the logarithmic mean crack length (LMCL), $\bar{c}$, and standard deviation for the population. Application of the $\chi^{2}$ test showed for each range that this parameter was less than the critical value at the $5 \%$ level of significance, i.e., in no case was the hypothesis of a log-normal distribution rejected at that level of confidence.

The specimen values of the log-normal distribution (ln) of the grain-boundary LMCL for tests at the nominal rate of

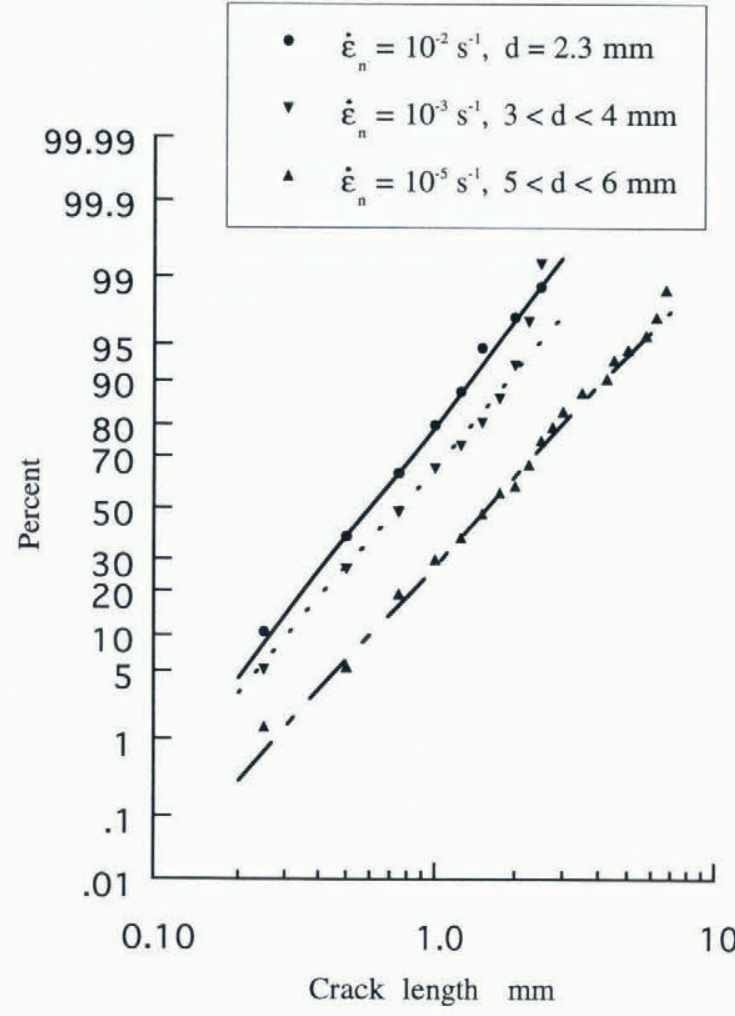

Fig. 5. Grain-boundary crack lengths, plotted on log-normal probability coordinates, for one specimen at $\dot{\varepsilon}_{\mathrm{n}}=10^{-2} \mathrm{~s}^{-}$; for all specimens in the grain-size range of $3-4 \mathrm{~mm}$, $\dot{\varepsilon}_{\mathrm{n}}=10^{3} \mathrm{~s}^{-1}$; and for all specimens in the grain-size range $5-6 \mathrm{~mm}, \dot{\varepsilon}_{\mathrm{n}}=10^{-5} \mathrm{~s}^{-1}$. The maximum stress and range in maximum strain are given in Table 3 for each rate; $T=-10^{\circ} \mathrm{C}$

$10^{4} \mathrm{~s}^{-1}$ are plotted against the $\ln$ of the grain-size in Figure 6 , along with the line obtained by a linear regression analysis. Shown as well are the lines from a linear regression analysis of the specimen values of the LMCL for the nominal rates $10^{-3}$ and $10^{-5} \mathrm{~s}^{-1}$. The corresponding equations and correlation coefficients are given in Table 4. These equations were used to calculate the mean LMCL for grain-sizes of $3,5,7$ and $9 \mathrm{~mm}$, and the resulting values are plotted against actual strain rate in Figure 7 . Included also are the means of the LMCLs for the tests conducted under constant-load conditions and for the two tests at the nominal rate of $10^{-2} \mathrm{~s}^{-1}$, all with average grain-size about $3 \mathrm{~mm}$. The results for this average grain-size indicate a maximum in the strain-rate dependence of the LMCL at a rate of $10^{-5}$ to $10^{6} \mathrm{~s}^{-1}$.

The grain-boundary LMCLs determined for the tests conducted at $-5^{\circ},-20^{\circ}$ and $-30^{\circ} \mathrm{C}$ are presented in Figure 8. Included also are the LMCLs for the six specimens, tested at $-10 \mathrm{C}$, that were used in the presentation of the dependence of the crack ratios on temperature, and the linear regression equation giving the dependence of the grain boundary LMCL on temperature. Only four data points appear for $-10^{\circ} \mathrm{C}$, as there were two specimens with a LMCL of $0.66 \mathrm{~mm}$ and two with a LMCL of $0.75 \mathrm{~mm}$. All tests were conducted at the nominal rate of $10^{-3} \mathrm{~s}^{-1}$, and the grain-size of each specimen was in the range $2.9-6.2 \mathrm{~mm}$.

There were not enough transcrystalline cracks per specimen to carry out the same crack-length analysis as was done for the grain-boundary cracks. The lengths of the trans- 
Table 3. Characteristics of the log-normal distribution for grain-boundary cracks for the constant-strain-rate tests at $-10^{\circ} \mathrm{C} ; \dot{\varepsilon}_{\mathrm{n}}$ is the nominal strain rate, $\varepsilon_{\mathrm{t}}$ is the total strain, $\sigma_{\mathrm{m}}$ is the maximum stress applied, $d$ is the range in grain-size, $N$ is the number of cracks, $\bar{c}$ is the LMCL and S.d. is the standard deviation of the log-normal distribution ( $\ln (\mathrm{mm})$ )

\begin{tabular}{ccccc}
\hline$d$ & $N$ & $\bar{c}$ & $\ln (\bar{c})$ & S.d. \\
$\mathrm{mm}$ & & $\mathrm{mm}$ & & \\
\end{tabular}

\begin{tabular}{|c|c|c|c|c|}
\hline \multicolumn{2}{|c|}{$\dot{\varepsilon}_{\mathrm{n}}=10^{2} \mathrm{~s}^{1}$} & \multirow{2}{*}{$\begin{array}{c}\sigma_{\mathrm{m}}=4.5 \mathrm{MPa} \\
0.57\end{array}$} & \multicolumn{2}{|c|}{$\left(4.8<\varepsilon_{\mathrm{t}}<5.1\right) \times 10^{-}$} \\
\hline $2-4$ & 130 & & -0.58 & 0.74 \\
\hline \multicolumn{2}{|c|}{$\dot{\varepsilon}_{\mathrm{n}}=10^{-3} \mathrm{~s}^{-1}$} & $\sigma_{\mathrm{m}}=4.3 \mathrm{MPa}$ & \multicolumn{2}{|c|}{$\left(4.1<\varepsilon_{\mathrm{t}}<6.1\right) \times 10^{-4}$} \\
\hline $2-3$ & 101 & 0.60 & -0.51 & 0.71 \\
\hline $3-4$ & 134 & 0.75 & -0.29 & 0.71 \\
\hline $4-5$ & 78 & 0.60 & -0.51 & 0.69 \\
\hline $5-6$ & 107 & 0.70 & -0.36 & 0.79 \\
\hline $6-7$ & 25 & 0.95 & -0.05 & 0.76 \\
\hline $7-9$ & 133 & 0.70 & -0.36 & 0.87 \\
\hline \multicolumn{2}{|c|}{$\dot{\varepsilon}_{\mathrm{n}}=10^{4} \mathrm{~s}^{-1}$} & $\sigma_{\mathrm{m}}=4.2 \mathrm{MPa}$ & \multicolumn{2}{|c|}{$\left(4.5<\varepsilon_{\mathrm{t}}<6.6\right) \times 10^{-4}$} \\
\hline $2-3$ & 168 & 0.69 & -0.37 & 0.68 \\
\hline $3-4$ & 54 & 0.89 & -0.12 & 0.69 \\
\hline $4-5$ & 19 & 1.13 & 0.12 & 0.89 \\
\hline $6-7$ & 94 & 1.04 & 0.04 & 0.99 \\
\hline 79 & 38 & 1.57 & 0.45 & 0.74 \\
\hline \multicolumn{2}{|c|}{$\dot{\varepsilon}_{\mathrm{n}}=10^{-5} \mathrm{~s}^{-1}$} & $\sigma_{\mathrm{m}}=3.0 \mathrm{MPa}$ & \multicolumn{2}{|c|}{$\left(4.2<\varepsilon_{t}<9.6\right) \times 10^{-4}$} \\
\hline 23 & 32 & 1.02 & 0.02 & 0.65 \\
\hline $3-4$ & 62 & 1.05 & 0.05 & 0.72 \\
\hline $4-5$ & 86 & 1.11 & 0.10 & 0.81 \\
\hline $5-6$ & 73 & 1.52 & 0.42 & 0.77 \\
\hline 78 & 42 & 2.33 & 0.85 & 0.87 \\
\hline
\end{tabular}

crystalline cracks for all specimens tested at a given nominal strain rate at $-10^{\circ} \mathrm{C}$ were combined for specimens of grainsize $<5 \mathrm{~mm}$ and of grain-size $>5 \mathrm{~mm}$. The $\mathrm{tr}-\mathrm{gb}$ cracks were included, as was done for the crack-type analysis. Fig-

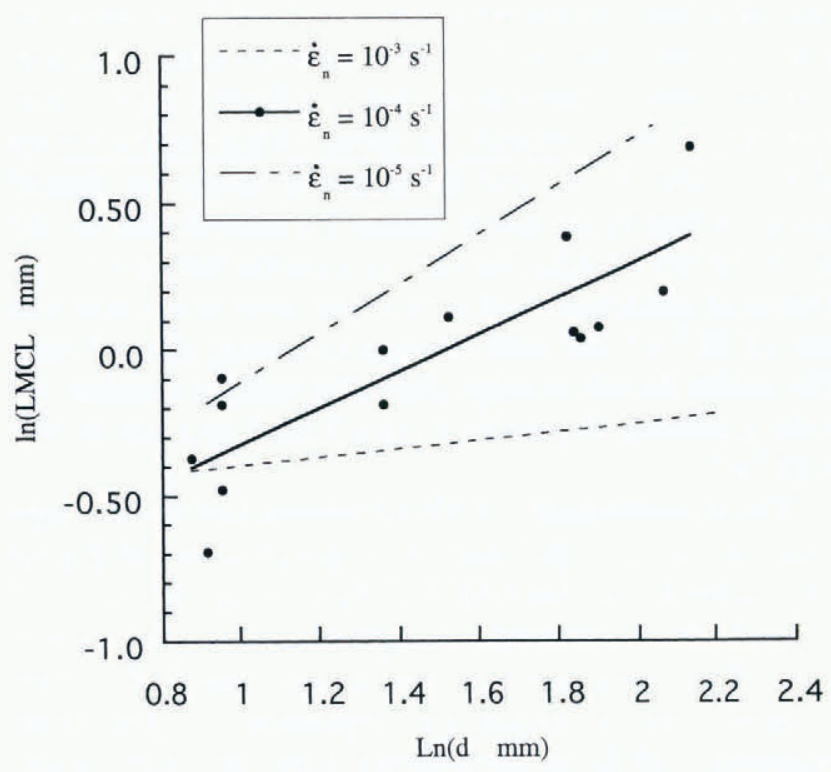

Fig. 6. Dependence of the $\ln$ of the grain-boundary LMCL, $\bar{c}$, on the $\ln$ of the grain-size, d, for the constant-strain-rate tests; individual values are shown for $\dot{\varepsilon}_{\mathrm{n}}=10^{-4} \mathrm{~s}^{-1} ; \mathrm{T}=-10^{\circ} \mathrm{C}$. The linear regression line is shown for each strain rate, and their equation and correlation coefficient are presented in Table 4.
Table 4. Linear regression equations and correlation coefficients, $R$, for the grain-size dependence of the LMCL, $\bar{c}$ $(\mathrm{mm})$, for given nominal strain rate, $\dot{\varepsilon}_{\mathrm{n}} ; \varepsilon_{\mathrm{t}} \sim 6 \times 10^{-4}$; $T=-10^{\circ} \mathrm{C} ;$ d is in $\mathrm{mm}$

\begin{tabular}{lll}
\hline Load condition & Equation & $R$ \\
\hline$\dot{\varepsilon}_{\mathrm{n}}=10^{-3} \mathrm{~s}^{-1}$ & $\ln (\bar{c})=-0.58+0.14 \ln (d)$ & 0.34 \\
$\dot{\varepsilon}_{\mathrm{n}}=10^{-4} \mathrm{~s}^{-1}$ & $\ln (\bar{c})=-0.95+0.63 \ln (d)$ & 0.84 \\
$\dot{\varepsilon}_{\mathrm{n}}=10^{-5} \mathrm{~s}^{1}$ & $\ln (\bar{c})=-0.95+0.84 \ln (d)$ & 0.79 \\
\hline
\end{tabular}

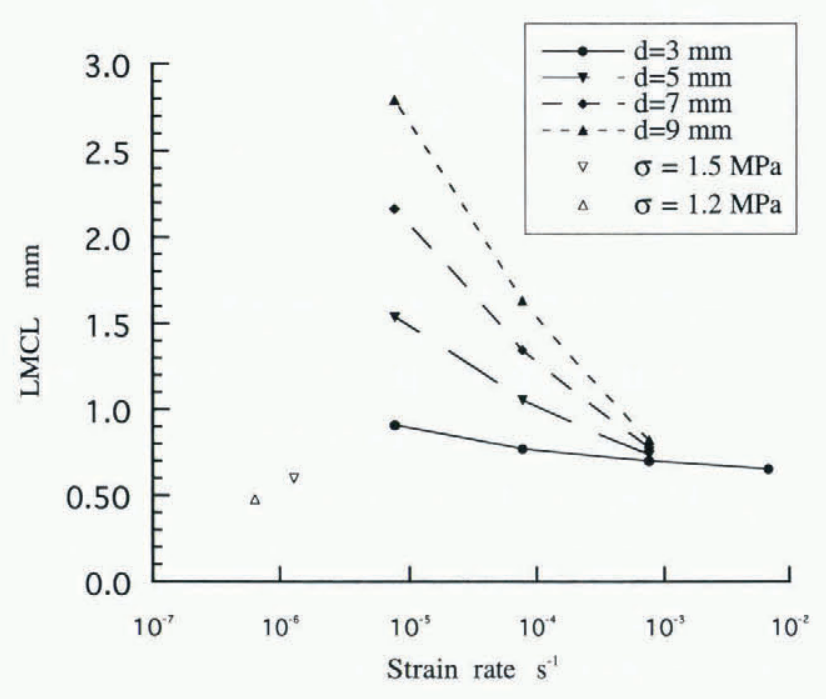

Fig. 7. Strain-rate dependence of the grain-boundary LMCL, $\bar{c}$, for a given grain-size; $T=-10^{\circ} \mathrm{C}$ for the constant-strainrate tests; $T=-9.5^{\circ} \mathrm{C}$ and $d \sim 3 \mathrm{~mm}$ for the constant-load tests at 1.2 and $1.5 \mathrm{MPa} ; \varepsilon_{\mathrm{t}} \sim 6 \times 10^{-4}$.

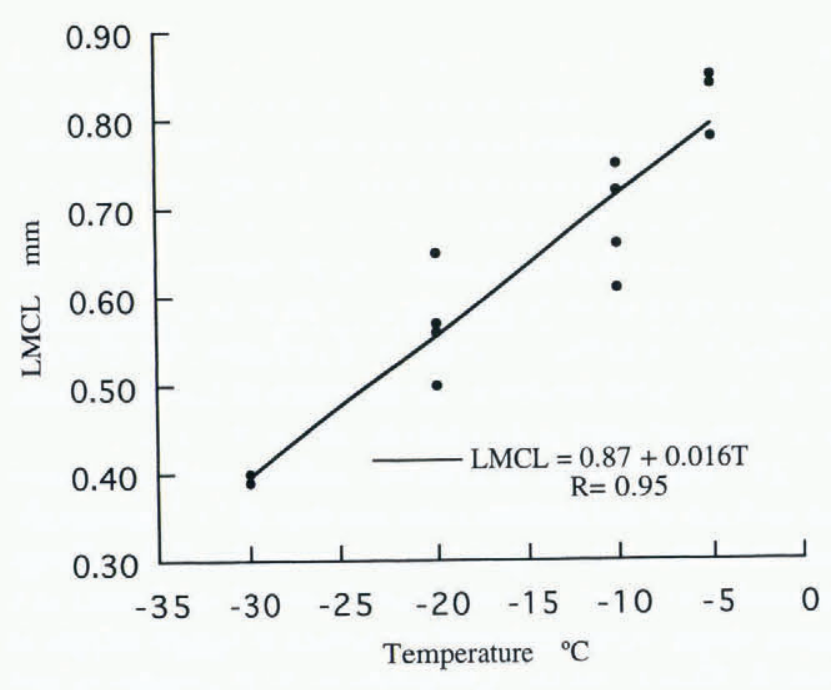

Fig. 8. Temperature dependence of the grain-boundary LMCL, $\bar{c} ; \dot{\varepsilon}_{\mathrm{n}}=10^{3} \mathrm{~s}^{-1}, \varepsilon_{\mathrm{t}} \sim 6 \times 10^{4}$, and grain-size is in the range 3.2- $6.2 \mathrm{~mm}$. The linear regression line and its equation are presented, along with the correlation coefficient, $R$.

ure 9 presents two sets of results on a log-normal coordinate system, along with the lines determined from the statistical analysis of the logarithms of the crack lengths. The LMCL and standard deviation for all the sets are presented in Table 5. This table indicates that the LMCL for the transcrystalline cracks of specimens of grain-size $<5 \mathrm{~mm}$, including those for the tests under constant loads of 1.2 and $1.5 \mathrm{MPa}$, 


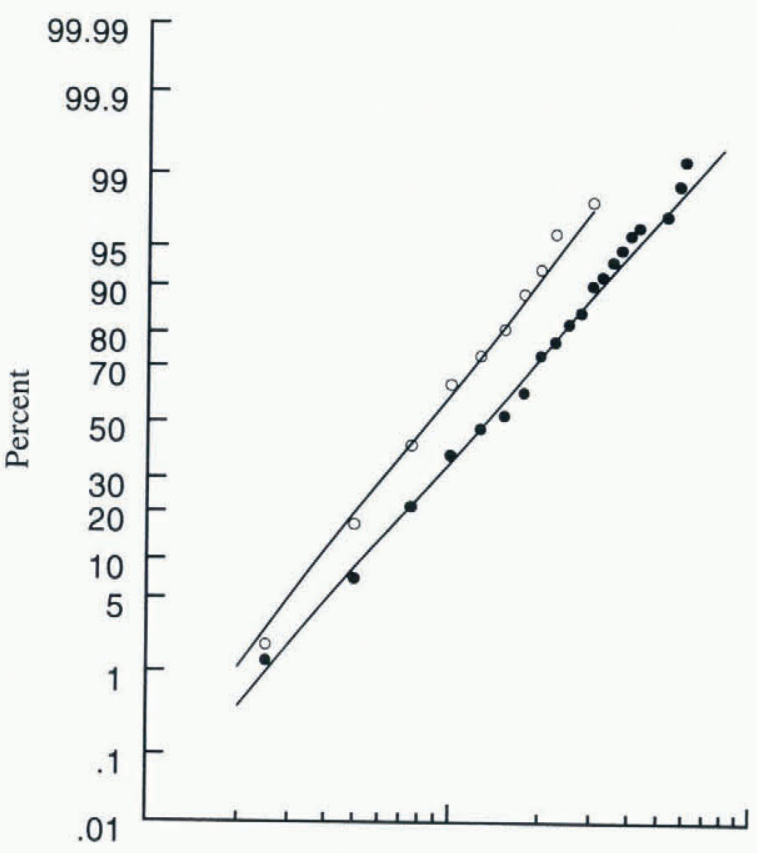

0.1 1

Crack length $\mathrm{mm}$

Fig. 9. Transcrystalline crack lengths, plotted on log-normal probability coordinates, for all specimens of grain-size $>5 \mathrm{~mm}, \dot{\varepsilon}_{\mathrm{n}}=10^{-3} \mathrm{~s}^{-1}(\mathrm{0})$, and for all specimens of grainsize $<5 \mathrm{~mm}, \dot{\varepsilon}_{\mathrm{n}}=10^{-5} \mathrm{~s}^{-1}(\bullet) ; \varepsilon_{\mathrm{t}} \sim 6 \times 10^{4} ; \mathrm{T}=-$ $10^{\circ} \mathrm{C}$.

have a maximum at a strain rate of $10^{-5}$ to $10^{-6} \mathrm{~s}^{-1}$, similar to that for the grain-boundary cracks.

The transcrystalline cracks were combined for the tests at each of the temperatures $-5^{\circ},-20^{\circ}$ and $-30^{\circ} \mathrm{C}$, and for the specimens tested at $-10^{\circ} \mathrm{C}$ that were used in the presentation of the temperature dependence of the LMCLs (Fig. 8). There were only ten transcrystalline cracks at $-20^{\circ} \mathrm{C}$ and nine at $-30^{\circ} \mathrm{C}$. A linear regression analysis gave

$$
\mathrm{LMCL}=1.14+0.25 T \quad(R=0.87)
$$

where $T$ is the temperature in ${ }^{\circ} \mathrm{C}$ and the LMCL is in $\mathrm{mm}$. This dependence is similar to that found for the grainboundary cracks.

The grain-boundary crack-length measurements for all specimens of grain-size $<5 \mathrm{~mm}$ and for grain-size $>5 \mathrm{~mm}$ were combined for each of the nominal strain rates $10^{3}, 10^{-4}$ and $10^{-5} \mathrm{~s}^{-1}$. The mean and standard deviation from the statistical analysis of the logarithms of the crack lengths are presented in Table 5. Presented also are the characteristics of the grain-boundary and transcrystalline crack populations for the tests carried out under constant stresses of 0.7 , $0.8,1.2$ and 1.5 MPa. The mean LMCL for the transcrystalline cracks is larger than for the corresponding grainboundary cracks in each case except one, but the relative difference tends to decrease with decreasing strain rate.

The difference between the actual value of the grainboundary LMCL and the mean value determined from the linear regression equations for the grain-size dependence, given in Table 4, was calculated for each test for the nominal rates $10^{-3}, 10^{-4}$ and $10^{-5} \mathrm{~s}^{-1}$ in the same manner as was done for the grain-boundary crack ratios. Table 6 gives the defining characteristics, $M_{1}$ and $M_{2}$, and the correlation coefficients from a linear regression analysis for an exponential curve fit to the percentages and differences plotted on nor-
Table 5. LMCL, $\bar{c}$, and standard deviation, S.d. $(\ln (\mathrm{mm}))$, for the log-normal distribution fit to the lengths of transcrystalline and grain-boundary cracks in data sets of specimens of grain-size, $d,<5 \mathrm{~mm}$ and $>5 \mathrm{~mm}$, for given average strain rates and strain of about $6 \times 10^{-4}$, except for stress of $0.8 \mathrm{MPa}\left(\varepsilon_{\mathrm{t}}=35 \times 10^{-4}\right)$, stress of $0.7 \mathrm{MPa}\left(\varepsilon_{\mathrm{t}} \sim 53 \times\right.$ $\left.10^{4}\right)$ and Cole (1986) $\left(\varepsilon_{\mathrm{t}}>25 \times 10^{-4}\right) ; \mathrm{T}=-10^{\circ} \mathrm{C}$ ( constant-strain-rate tests) $=-9.5^{\circ} \mathrm{C}($ constant-load tests $)$, $=-5^{\circ} \mathrm{C}$ (Cole, 1986); Rt is the ratio of the transgranular mean crack length to the corresponding grain-boundary value

\begin{tabular}{|c|c|c|c|c|}
\hline \multirow[t]{3}{*}{ Strain rate or stress } & \multicolumn{2}{|c|}{ Grain boundary } & \multicolumn{2}{|c|}{ Transcrystalline } \\
\hline & $\bar{c}$ & S.d. & $\bar{c}$ & S.d. \\
\hline & $\mathrm{mn}$ & & $\mathrm{mn}$ & \\
\hline
\end{tabular}

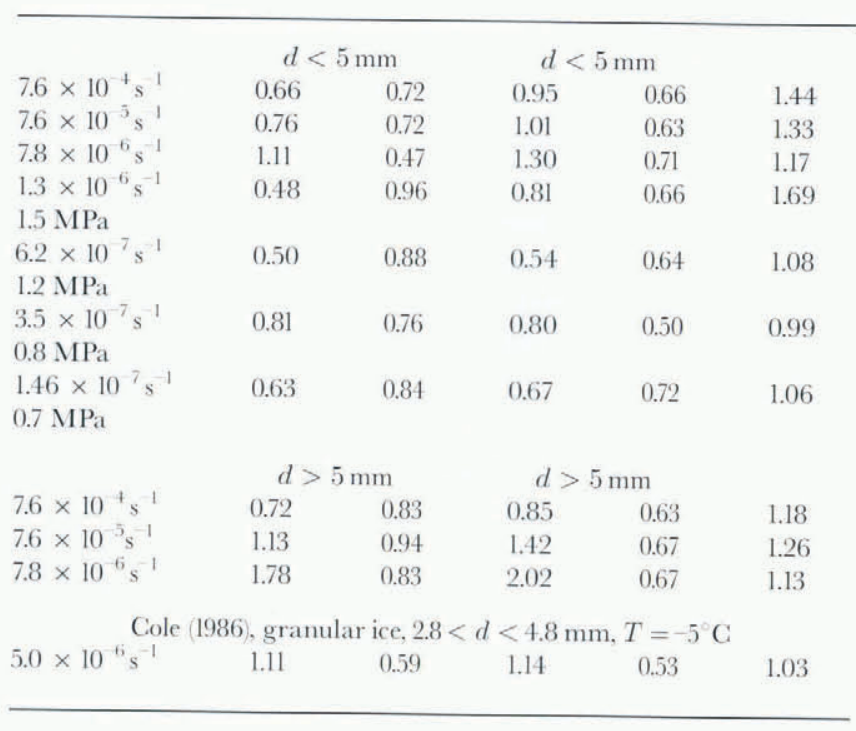

mal probability coordinates. Given also are the means and standard deviations from a statistical analysis of the differences. $M_{1}$ and $M_{2}$ agree closely with the corresponding means and standard deviations, as was the case for the crack ratios. This agreement in the results of the regression analysis and the statistical analysis for both the crack ratios and the LMCLs indicates that the variations in the differences between specimens, for the same test conditions, can be described with a high level of confidence by the normal distribution. The ratios and the LMCLs behave as random variables. This behaviour is consistent with the relative crystallographic orientation of adjacent grains having a random distribution.

Table 6. The defining characteristics, $M_{1}$ and $M_{2}$, and the correlation coefficients, $R$, from an exponential curve fit to the differences, plotted on normal probability coordinates, between the test values of the grain-boundary logarithmic mean crack length and the corresponding mean value determined from the linear regression equations given in Table 4. Given also are the corresponding means and standard deviations (S.d.) from a statistical analysis of the differences; $\varepsilon_{\mathrm{t}} \sim 6 \times 10^{4} ; \mathrm{T}=-10^{\circ} \mathrm{C}$

\begin{tabular}{llllll}
\hline Load condition & $M_{1}$ & $M_{2}$ & $R$ & Mean & S.d. \\
\hline$\dot{\varepsilon}_{\mathrm{n}}=10^{-3} \mathrm{~s}^{-1}$ & 0.008 & 0.16 & 0.98 & 0.008 & 0.16 \\
$\dot{\varepsilon}_{\mathrm{n}}=10^{-1} \mathrm{~s}^{-1}$ & -0.006 & 0.19 & 0.97 & -0.006 & 0.19 \\
$\dot{\varepsilon}_{\mathrm{n}}=10^{-5} \mathrm{~s}^{-1}$ & -0.003 & 0.22 & 0.98 & -0.003 & 0.23 \\
\hline
\end{tabular}




\section{DISCUSSION}

The maximum strain imposed on each specimen was $4.1 \times 10^{-4}$ to $6.6 \times 10^{-4}$ for nominal strain rate greater than $10^{-4} \mathrm{~s}^{-1}$, and $4.2 \times 10^{-4}$ to $9.6 \times 10^{-4}$ for the nominal rate $10^{5}$ $\mathrm{s}^{-1}$. It was found that the elastic modulus increased with grain-size (Gold, 1994), and as the maximum stress was always the same for each nominal strain rate, this would account for some of the spread in values. There was a tendency for the crack-length distribution curves to curl upward at the upper end, indicating a smaller number of longer cracks than would be predicted by a log-normal distribution. The tendency was greater for the transcrystalline than for the grain-boundary cracks. This would be expected if the length of cracks was limited by the length of the grain boundary or the size of the grains. The length of a crack was not fully uniform, also, but no attempt was made to relate the measured valuc to a mean value. In spite of these factors, the $\log$-normal distribution was a reasonable approximation to the observed distribution.

Cole (1986) presented histograms giving the lengths of grain-boundary and transcrystalline cracks formed in granular-ice specimens subjected to creep under constant load at $-5^{\circ} \mathrm{C}$. Crack lengths, obtained from the histograms, were combined for four specimens of grain-size $2.8-4.6 \mathrm{~mm}$, strained to $25 \times 10^{-4}$ to $100 \times 10^{-4}$ at a minimum rate of $2.1 \times 10^{-6}$ to $8.5 \times 10^{-6} \mathrm{~s}^{-1}$. The log-normal distribution was found to be a reasonable description for both the grainboundary and the transcrystalline crack populations. Their mean and standard deviation are given in Table 5 .

Cole (1988) has shown that for strain rate greater than about $10^{-5} \mathrm{~s}^{-1}$, there is insufficient time during a strain of less than $10^{-3}$ for dislocation pile-ups to be a significant process for crack initiation in ice. For such strain rates, recoverable strain in grain boundaries and grains, as demonstrated by the anelastic or delayed elastic behaviour (Sinha, 1979; Cole, 1991, 1993; Gold, 1994), as well as anisotropy in the elastic constants, would appear to be more appropriate reasons for the formation of cracks. For both these situations, stress concentrations can be expected to develop at the triple points (Tvergaard and Hutchinson, 1988). These locations, therefore, would be preferred sites for the formation of cracks, as was found for the grain-boundary cracks.

When considering criteria for crack formation, a necessary condition is that the elastic strain energy available for the event at the time of initiation is greater than or equal to the new crack surface area times the effective surface energy. Because the imposed strain in the present work is essentially two-dimensional, the length of a crack would be a direct measure of that energy.

Frost and Smith (1993) have investigated the crack nucleation process for grain-boundary cracks in columnargrain ice using an elastic analysis and the method employed by Tvergaard and Hutchinson (1988). They show that the energy at nucleation is given by:

$$
U_{\text {nucl }}=J_{\text {nucl }} a_{\text {crit }}[(2 \lambda+1) /(2 \lambda+2)]
$$

where $U_{\text {nucl }}$ is the energy required for the formation of a crack of length $2 a_{\text {crit }}, J_{\text {mucl }}$ is the strain-energy release rate at the time of formation $\left(J_{\text {nucl }} \geq 2 \gamma_{\mathrm{gb}}\right.$, where $\gamma_{\mathrm{gb}}$ is the grain-boundary energy) and $\lambda$ is the exponent giving the strength of the singularity at the precursor tip. The value of $\lambda$ in their analysis is determined by the geometry and relative crystallographic orientation of the grains forming a triple point, and the values of the elastic constants of the ice crystal. Gupta and others (1993), using the same method of analysis, have shown that for columnar-grain ice the most critical value of $\lambda$ occurs at triple points at which the grain boundaries are $120^{\circ}$ to each other.

From Frost and Gupta (1993), the critical strain-energy release rate is given by

$$
J_{\text {nucl }}=\frac{1-\nu^{2}}{E} \frac{\sigma_{\mathrm{d}}^{2}}{d^{2 \lambda}} Q^{2}(\lambda) a 2 \lambda+1_{\text {crit }}
$$

where $E$ is the elastic modulus, $\nu$ is Poisson's ratio, $\sigma_{\mathrm{d}}$ is a constant that depends on the applied stress and grain shape, $d$ is the grain-size and $Q(\lambda)$ is a parameter that depends on the strength of the singularity at the tip of the precursor. Assume that all the effect of grain-size is given by the term $d^{2 \lambda}$. Under this condition, $J_{\text {nucl }}$ and $U_{\text {nucl }}$ for the formation of a crack of length $2 a_{\text {crit }}$ are proportional to $d^{-2 \lambda}$. For the uniaxial, compressive stress condition, the energy to form the crack must come from the local strain energy, i.e. $U_{\text {nucl }}$. If the distribution in the lengths of the cracks is related directly to the distribution in $U_{\text {nucl }}$, the LMCL should have the same dependence on $d$ as the corresponding value of $U_{\text {nucl }}$, i.e. $\alpha d^{-2 \lambda}$. Referring to the plot of $\ln (\mathrm{LMCL})$ against $\ln (d)$ (Fig. 6; Table 4), the value of $-2 \lambda$ for the three nominal rates $10^{3}, 10^{-4}$ and $10^{-5} \mathrm{~s}^{-1}$ is, respectively, $0.14,0.63$ and 0.84 . This gives for $\lambda$ the values of $-0.07,-0.31$ and -0.42 , all within the expected range of 0 to -0.5 .

Picu and Gupta (1995) and Elvin and Sunder (1996) present models for the formation of microcracks in columnargrain ice. Both models assume that shear occurs over the full grain-boundary facet and show that this produces a larger crack-nucleating stress at the triple point than does elastic anisotropy. The models predict a grain-size dependence of $d^{-1 / 2}$ for the stress for the formation of a microcrack. Gold and others (1993) found that the stress and strain to the formation of the first crack at the nominal strain rate $10^{-3} \mathrm{~s}^{-1}$ had a significant correlation with $d^{-1 / 2}$ and that their results agreed well with those of Kalifa and others (1991) for granular ice. Gold (1994) also found a significant dependence of the elastic moduli on grain-size at the same nominal rate of strain.

The present work covers the range of the crack-forming process that can be described as nucleation and "pop-in". No evidence was seen either during the test or on the video record of it, of crack propagation after pop-in for the stress levels applied (about $60 \%$ of the failure value) and nominal strain rate greater than $10^{-5} \mathrm{~s}^{-1}$. Figure 7 indicates that the grain-boundary LMCLs tend to a value of about $0.75 \mathrm{~mm}$ for strain rate greater than $10^{-3} \mathrm{~s}^{-1}$, that is independent of grain-size. Assuming that crack length is a valid measure of the associated minimum strain energy, what Figures 6 and 7 indicate is that the logarithmic mean strain energy for grain-boundary crack formation, and, therefore, the accompanying stress field, become increasingly independent of grain-size with increasing strain rate, in agreement with the decreasing value for the strength of the singularity, as given by $\lambda$. This behaviour would suggest that the nucleation process for grain-boundary cracks becomes increasingly localised to the sites of the stress singularities with increasing strain rate. A value of -0.07 for $\lambda$ at the nominal strain rate of $10^{-3} \mathrm{~s}^{-1}$ is the order to be expected for a relatively small elastic anisotropy (Tvergaard and Hutchinson, 1988). Equation (3) and Figure 6 do raise questions con- 
cerning the meaning for $\lambda$ for increasing delayed elastic and viscous behaviour.

One of the problems for modelling crack nucleation for ice has been the apparent lack of precursors at the stress levels observed in practice. This difficulty appears to be reduced significantly if grain-boundary shear and relaxation are taken into consideration (Picu and Gupta, 1995; Elvin and Sunder, 1996). One possibility that does not appear to have been considered for ice, however, is a time- and stress-dependent decrease in the effective grain-boundary energy. This could occur, for example, by the formation and coalition of vacancies in the high tensile stress region of stress singularities. Such a process would explain why some characteristics of crack formation, such as the time to formation of the first crack (Gold, 1967, 1972a), appear to be associated with a thermally activated process. It would be consistent with the initial relaxation in the elastic modulus of ice found for strain rates greater than $10^{-2} \mathrm{~s}^{-1}$ and the transition from crack formation to cavity formation with decreasing strain rate (Gold, 1963). In the present work, some examples were observed at triple points in specimens deformed at the nominal rate of $10^{-3} \mathrm{~s}^{-1}$ of linear features about $0.1 \mathrm{~mm}$ wide and several $\mathrm{mm}$ long, in grain boundaries tending to be parallel to the direction of the stress, and of rows of bubbles of the type postulated by Elvin and Sunder (1996). If this is what is taking place, the crackforming process would begin when the stress field induced at a singularity starts to create vacancies. Crack nucleation would occur when the effective grain-boundary energy over a potential crack length, $2 a$, is reduced to a value that satisfies Equation (2). For this model, a sufficient condition for deformation-induced crack formation in ice at temperatures above $-50^{\circ} \mathrm{C}$ would be that it be polycrystalline.

The analysis showed that the probability of a transcrystalline crack forming in the first $9 \times 10^{4}$ of strain, decreased with increase in strain rate, decrease in temperature and decrease in grain-size, the converse of what was observed for the grain-boundary cracks. This indicates the two crack populations are formed by different crackforming processes with different dependencies on grain-size, strain rate and temperature.

The increased permanent strain with decrease in strain rate and increase in temperature is associated with the increase in the relative proportion of transcrystalline cracks, indicating that dislocations may be an important cause for their formation (Gold, 1967). Table 5 shows that, for the same load conditions, the transcrystalline cracks have a larger mean LMCL than do the grain-boundary ones. This, and the fact that the surface energy for transcrystalline cracks is about $65 \%$ larger than for grain-boundary cracks (Hobbs, 1974), shows that, for a given strain rate and strain, the transcrystalline crack-causing mechanism must induce, on average, a larger amount of strain energy by the time of formation than does the grain-boundary crack-forming process. It would appear that the majority of the grainboundary cracks were caused by forces tending to separate grains, and the transcrystalline cracks by forces tending to deform grains in shear.

The marked changes in the crack ratios and statistical characteristics of the crack lengths occurred over the same range of strain rate as the brittle to ductile transition in the deformation behaviour for this type of ice. This suggests that the changes and transition are controlled by the same deformation processes. The change in the statistical characteris- tics of the crack populations indicates that the underlying cause may be the time and temperature dependence of the response of dislocations to stress.

The analysis of the time dependence of the elastic modulus for the constant strain-rate tests (Gold, 1994) showed that, for stress and strain of up to $60 \%$ of failure in the brittle range of behaviour, the effective elastic modulus was constant in spite of the formation of cracks. It would be expected, however, that their formation would have an important role in failure. Two specimens were loaded to failure at the nominal rate of $10^{3} \mathrm{~s}^{-1}$. In one case the failure load was $6.1 \mathrm{MPa}$ and in the other $5.8 \mathrm{MPa}$. The specimens were enclosed in clear vinyl plastic film to keep them intact after failure. Failure was abrupt and the video record of the tests showed that it occurred by splitting and shear in the manner described by Schulson (1990). Several years ago, the author conducted similar tests in a screw-driven testing frame using the same type of ice. In this more compliant testing machine, failure was explosive and specimens disintegrated into small particles. One specimen was enclosed in clear vinyl film and it remained intact after failure. In this case, there was no splitting or shear. Rather, it appeared that the grain boundaries were all completely cracked. These observations, and the work of Schulson, bring out the marked dependence of the nature of the final failure process on ice type, crack damage, specimen geometry, conditions of loading and the characteristics of the testing machine. For the brittle range of behaviour, in particular, the transition from random to non-random for the crack populations may be an important criterion for failure.

\section{CONCLUSIONS}

Grain boundaries were found to be the principal location for cracks formed in columnar-grain ice strained to less than $10^{-3}$ at a constant rate greater than $7.8 \times 10^{-6} \mathrm{~s}^{-1}$, by a load applied perpendicular to the long axis of the grains. Under these conditions, practically all of the grain-boundary cracks have at least one edge at a triple point. The proportion of grain-boundary cracks increases with increasing strain rate, decreasing grain-size and decreasing temperature, and is a random variable for tests with the same conditions of loading. It approaches $100 \%$ for a strain rate of $10^{-2} \mathrm{~s}^{-1}$ and temperature of $-10^{\circ} \mathrm{C}$.

The distribution in crack lengths for the grain-boundary and transcrystalline crack populations is, with good confidence, log-normal. This suggests that the strain energy associated with the formation of the cracks has, also, a similar distribution function. For strain rate greater than $7.8 \times$ $10^{-6} \mathrm{~s}^{-1}$, the LMCL for both populations decreases with increasing strain rate and decreasing grain-size and temperature. The LMCLs at a strain of about $6 \times 10^{-4}$ and temperature of $-10^{\circ} \mathrm{C}$ have a maximum between the strain rates of $10^{-5}$ and $10^{6} \mathrm{~s}^{-1}$. In the ductile range of behaviour, they decrease with decreasing strain rate. For the brittle range of behaviour and to a strain of $6 \times 10^{-4}$ at least, the LMCL is a random variable. This characteristic probably extends to larger strains with increasing ductile behaviour.

The principal differences between the grain-boundary and transcrystalline crack populations are the dependence of their relative number on grain-size, strain rate and temperature and, for a given amount of strain, the mean local strain energy required for their formation. The dependence 
of the crack ratios and lengths on strain rate, grain-size and temperature is consistent with the processes for the formation of grain-boundary cracks being, primarily, those associated with elastic and delayed elastic anisotropy and stress singularities, particularly at grain-boundary triple points, and, for the transcrystalline cracks, those associated with dislocation processes. For the conditions of the tests, the formation of a crack was a manifestation of a random sampling of precursors and crack-forming processes.

\section{ACKNOWLEDGEMENTS}

The author expresses his gratitude to the Institute for Marine Dynamics of the National Research Council of Canada and, in particular, to Dr S. Jones, for the opportunity to carry out this study of crack formation in ice. He is indebted to Dr M. Williams for her comments on the statistical analysis of the results and to Mr T. Slade for his most valuable assistance with preparing samples and carrying out the tests.

\section{REFERENCES}

Cole, D. M. 1986. Effect of grain size on the internal fracturing of polycrystalline ice. CRREL Rep. 86-5.

Cole, D. M. 1988. Crack nucleation in polycrystalline ice. Cold Reg. Sii. Technol., 15 (1), $79-87$.

Cole, D. M. 1991. Anelastic straining in polycrystalline ice. In Sodhi, D. S., ed. Cold Regions Engineering. Proceedings of the Sixth International Specialty Conference, ...,West Lebanon, NH, February 26-28, 1991. New York, American Society of Civil Engineers, 504-518.

Cole, D. M. 1993. The effect of creep on the constitutive behavior of saline ice at low temperature. In Ice mechanics. Vol. AMD-163. New York, American Society of Mechanical Engineers. Applied Mechanics Division, $261-271$.

Elvin, A. A. and S. S. Sunder. 1996. Microcracking due to grain-boundary sliding in polycrystalline ice under uniaxial compression. Acta Metall. Materialia, 44 (1), 43-56.

Frost, H.J. and V. Gupta. 1993. Crack nucleation mechanisms and fracture toughness measurements in freshwater ice. In Ice mechanics. Vol. A.MD-163. New York, American Society of Mechanical Engineers. Applied Mechanics Division, $235-250$.

Frost, H.J. and T. R. Smith. 1993. Crack nucleation in columnar ice. In IAHR 92. 11th International Symposium on Ice, Banff, Alberta, Canada, June 15-19, 1992. Proceedings. Vol. 2. Edmonton, Alta, University of Alberta. Department of Civil Engineering, 1075-1086.

Gold, L. W. 1960. The cracking activity in ice during creep. Can. J. Phys., $38(9), 1137-1148$.

Gold, L.W. 1963. Deformation mechanisms in ice. In Kingery, W. D., ed. Ice and snow: properties, processes, and applications. Cambridge, MA, M.I.T. Press, 8-27.

Gold, L. W. 1966. Dependence of crack formation on crystallographic orientation for ice. Can. J. Phys., 44 (11), 2757-2764.

Gold, L.W. 1967. Time to formation of first cracks in ice. In Ōura, H., ed. Physics of snow and ice. Vol. 1, Parl 1. Sapporo, Hokkaido University. Institute of Low Temperature Science, 359-370.

Gold, L.W. 1972a. The failure process in columnar-grained ice. (Ph.D. thesis, McGill University.)

Gold, L.W. 1972b. The process of failure of columnar-grained ice. Philos. Mag., 26 2), 311-328.

Gold, L.W. 1994. The elastic modulus of columnar-grain fresh-water ice. Ann. Glaciol., 19, $13-18$.

Gold, L. W., S.J. Jones and T. D. Slade. 1993. A comparison of crack initiation conditions for columnar-grain and granular ice. In IAHR 92. 11th International Symposium on Ice, Banff, Alberta, Canada, fune 15-19, 1992. Proceedings. Vol. I. Edmonton, Alta, University of Alberta. Department of Civil Engineering, $200-209$.

Gupta, V., R. C. Picu and H. J. Frost. 1993. Crack nucleation mechanisms in saline ice. In Ice mechanics, Vol. A.MD-163. New York, American Society of Mechanical Engineers. Applied Mechanics Division, 199-216.

Hobbs, P.V. 1974. Ice physics. Oxford, Clarendon Press.

Kalifa, P., P. Duval and M. Ricard. 1989. Crack nucleation in polycrystalline ice under compressive stress states. In Sinha, N. K., D. S. Sodhi and J. S. Chung, eds. Proceedings of the Eighth International Conference on Offshore Mechanics and Arctic Engineering.... The Hague, The Netherlands, March 1.9-23, 1989. Vol. IV. Arctic and polar technology. New York, American Society of Mechanical Engineers, 13-21.

Kalifa, P., S. J. Jones and T. D. Slade. 1991. Microcrack nucleation in granular ice under uniaxial compression: effect of grain-size and temperature. Ann. Glaciol., 15, 222229.

Kuroiwa, D. 1964. Internal friction in ice. Contrib. Inst. Low Temp. Sci., Ser. A 18. Nakamura, T. and O. Abe. 1979. A grain-boundary relaxation peak of Antarctic Mizuho ice observed in internal friction measurements at low frequency. J. Fac. Sci., Hokkaido Lniv., Ser.VII (Geophys.), 6 1), 165-171.

Picu, R. C. and V. Gupta. 1995. Crack nucleation in columnar ice due to elastic anisotropy and grain boundary sliding. Acta Metall. Materialia, $43(10), 3783-3789$.

Schulson, E. M. 1990. The brittle compressive fracture of ice. Acta Metall. Materialia, 38 (10), 1963-1976.

Sinha, N. K. 1979. Grain boundary sliding in polycrystalline materials. Philos. Mag. A, 40 6), 825-842.

Sinha, N.K. 1988. Crack-enhanced creep in polycrystalline material: strain-rate sensitive strength and deformation of ice. J. Mater. Sci., $23(12,4415-4428$.

Sinha, N. K. 1990. Micro-fracturing and creep dilatation in polycrystalline columnar-grained and equi-axed ice. In Wilshire, B. and R.W. Evans, eds. Proceedings, th Conference on Creep and Fracture of Engineering Materials, 1-6 April 1990), Swansea, U.K. London, Institute of Metals, $345-354$.

Smith, T. R. and E. M. Schulson. 1994. Brittle compressive failure of saltwater columnar ice under biaxial loading]. f. Glaciol., 40 (135), 265- 276.

Tvergaard, V. and J.W. Hutchinson. 1988. Microcracking in ceramics induced by thermal expansion and elastic anisotropy. 7. Am. Ceram. Soc., $71(3), 157-166$. 